\title{
Comportamentos interespecíficos entre Callithrix jacchus (Linnaeus) (Primates, Callitrichidae) e algumas aves de Mata Atlântica, Pernambuco, Brasil
}

\author{
Rachel M. de Lyra-Neves '; Maria A.B. Oliveira ${ }^{2}$; Wallace R. Telino-Júnior '; Ednilza M. dos Santos ${ }^{3}$ \\ 1 Unidade Acadêmica de Garanhuns, Universidade Federal Rural de Pernambuco. Avenida Bom Pastor, Mundaú, \\ 55296-901 Garanhuns, Pernambuco,Brasil.E-mail: rmlneves@uag.ufrpe.br, telinojr@uag.ufrpe.br \\ 2 Departamento de Morfologia e Fisiologia Animal, Universidade Federal Rural de Pernambuco. Rua Dom Manoel de \\ Medeiros, Dois Irmãos, 52171-900 Recife, Pernambuco, Brasil. E-mail: adelia@dmfa.ufrpe.br \\ ${ }^{3}$ Unidade Acadêmica de Serra Talhada, Universidade Federal Rural de Pernambuco. Fazenda Saco, 56900-000 Serra \\ Talhada, Pernambuco, Brasil. E-mail: ednilzamaranhao@yahoo.com.br
}

\begin{abstract}
Interspecific behaviour between Callithrix jacchus (Linnaeus) (Callitrichidae, Primates) and some birds of the Atlantic Forest, Pernambuco State, Brazil. The observations cover a period of two years, monitoring groups of marked common marmosets in eight hour/day periods. Six types of events were recorded: marmoset predation; bird predation; foraging competition; food sharing; use of avian nest for nocturnal marmoset rest and mutual pursuit. All pooled events showed highly significant differences between season and vegetation strata. KEY WORDS. Ant-following; interaction; marmoset; predation.
\end{abstract}

RESUMO. As observações ocorreram no período de dois anos, monitorando grupos marcados de sagüis durante oito horas por dia. Foram registrados seis tipos de eventos: predação de sagüiis; predação de aves, disputa de área de forrageio e recurso alimentar; compartilhamento de área de forrageio e recurso alimentar; perseguição branda e utilização de ninho de ave como local de pernoite dos sagüis. Os eventos agrupados obtiveram diferenças significativas entre as estações do ano e os estratos ocupados.

PALAVRAS-CHAVE. Interação; predação; sagüis; seguidores de correição.

Estudos de inter-relações, particularmente aqueles que envolvem as interações entre animais e plantas, são bastante comuns (Piratelli \& Pereira 2002, Machado \& Lopes 2003, Vicente et al. 2003, Siqueira Filho \& Machado 2004). Relações interespecíficas com animais contemplam, geralmente, associações de parasito-hospedeiro (Lyra-Neves et al. 2000, 2003, 2005). Estudos de interações entre grupos vertebrados voltados às associações de predação, mutualismo e comensalismo relacionados a algumas variáveis ecológicas no Brasil são poucos a exemplo de Passos (1997) no sudeste e Hankerson et al. (2006) no nordeste. Para o estado de Pernambuco nada se tem relacionado a este tema.

Na Estação Ecológica do Tapacurá dois grupos taxonômicos, primatas e aves, já foram amplamente estudados. O estudo da avifauna é bem documentado em Tapacurá. Já o sagüido-nordeste tem sido alvo de pesquisa desde 1976 na Estação Ecológica do Tapacurá (e.g. Stevenson \& Poole 1976, Stevenson $\&$ Rylands 1988). Entretanto, nenhuma pesquisa voltada ao estudo da interação entre aves e sagüis na referida área havia sido realizada até o momento.

Desta forma, esta pesquisa traz informações sobre as relações existentes entre a classe aves e Callithrix jacchus (Linnaeus
1758) (Callitrichidae) tendo como objetivo o estudo do repertório comportamental interespecífico em hábitat natural, além de verificar a influência de variáveis ecológicas sobre os padrões comportamentais destes dois grupos.

\section{Área de estudo}

\section{MATERIAL E MÉTODOS}

A Estação Ecológica do Tapacurá está situada a $34^{\circ} 60^{\prime} \mathrm{W}$ e $08^{\circ} 07^{\prime}$ S, é um campus avançado da Universidade Federal Rural de Pernambuco e localiza-se no município de São Lourenço da Mata, Zona da Mata, a $54 \mathrm{~km}$ do Recife, capital pernambucana. Possui 428 ha de área, divididos pelo Açude de Tapacurá em dois fragmentos remanescentes da Mata Atlântica, denominados Mata do Toró e Mata do Camocim.

A pesquisa foi desenvolvida na porção sul da Mata do Camocim conhecida localmente por Mata do Alto da Buchada. Esta área possui 80 ha dos quais 22 foram trilhados através de um sistema de transectos (abertos nos sentidos N-S e L-O) em grades de 50 x 50 m, identificados alfa-numericamente (SCALON et al. 1989, 1991).

A Estação Ecológica de Tapacurá é classificada como área de Floresta Estacional Semidecidual de Terras Baixas (Veloso et 
al. 1991) possui clima do tipo As' com precipitação média anual de $1300 \mathrm{~mm}$ ao ano e seis meses com menos de $100 \mathrm{~mm}$ (RoDAL et al. 2005). Para o Estado de Pernambuco o período chuvoso se concentra entre os meses de março e agosto e período de estiagem entre os meses de setembro e fevereiro. Apresenta vegetação de mata seca, predominantemente arbórea, atingindo cerca de $30 \mathrm{~m}$ de altura, com um estrato intermediário bastante denso, constituído por espécies escandentes (ANDrade-Lima 1970). Possui três estratos arbóreos mais ou menos densos com maior riqueza concentrada nas espécies das famílias Bignoniaceae, Sterculiaceae, Leguminosae (Latu sensu) e Myrtaceae; um estrato arbusto-arbustivo representado em sua maioria por espécies das famílias Rubiaceae, Melastomataceae, Erythroxylaceae e Euphorbiaceae; um estrato herbáceo na maioria composto por Cyperaceae; lianas e trepadeiras maioria Malphigiaceae e por fim as epífitas representadas pelas Araceae e Bromeliaceae (Rodal et al. 2005). A vegetação herbácea está presente na maioria das áreas abertas, com penetração de luz. Em particular, para a área do alto da Buchada a mata primária sofreu corte seletivo e encontra-se em processo de regeneração natural, nela também pode ser encontrada árvores frutíferas exóticas (mangueiras, jaquiras, etc.) que foram introduzidas por antigos funcionários que moravam dentro da Estação em pequenos sítios.

\section{Métodos}

A pesquisa foi realizada entre setembro de 1994 e janeiro de 1996 e entre setembro de 2001 e agosto de 2002, totalizando um período de 30 meses e 5040 horas de observação. Para o estudo em campo foram realizadas identificações dos sagüis e das aves e observações dos padrões comportamentais.

A identificação dos sagüis deu-se por colares de placas e/ ou tricotomia e tatuagem, o que permitiu o reconhecimento individual dos componentes de cinco grupos sociais, inclusive quanto ao seu status hierárquico, sexo e idade. Para os indivíduos nascidos no período do estudo a marcação foi efetuada durante a amostragem desta pesquisa levando-se em consideração o método aplicado por M.A.B. Oliveira (dados não publicados, 1995). Os grupos sociais analisados estatísticamente quanto à predação de aves foram: 1) Esmirradins - grupo formado por no máximo oito membros. Participantes nos eventos: ZV (macho reprodutor), OQ (macho reprodutor), QS (fêmea reprodutora) e um infante (sexo indeterminado); 2) Esperancins - grupo formado por no máximo 13 membros. Participantes em eventos: WT (macho reprodutor), SP (macho reprodutor), VS (Fêmea adulta não reprodutora), TQ (Fêmea adulta não reprodutora); 3) Espivitadins - grupo formado por no máximo nove membros. Participantes em eventos: LM (macho reprodutor), B (fêmea infante); 4) Alagadins - grupo periférico formado por no máximo seis membros. Participantes em eventos: Z (fêmea infante).

A identificação das aves foi realizada por meio de guias especializados e de listas da avifauna local, além da experiência de campo dos pesquisadores. A nomenclatura da aves foi dada segundo SGRIST (2006).

As observações dos padrões comportamentais foi realiza- da com auxílio de binóculos após o reconhecimento dos grupos de sagüis e identificação das aves. O observador acompanhava os grupos de sagüis notificando todos os eventos interespecíficos ocorridos.

Os eventos interespecíficos foram agrupados em seis diferentes categorias: Evento I - predação de sagüis; Evento II predação de aves; Evento III - disputas de recurso alimentar (disputas com ações agonísticas entre representantes dos dois grupos estudados envolvendo a área de forrageio ou o recurso alimentar); Evento IV - Divisão de área de forrageio (permanência de representantes dos dois grupos em uma determinada área de forrageio sem, no entanto, apresentação de posturas agressivas entre eles em decorrência do recurso almejado); Evento V - perseguição branda (perseguição entre representantes dos dois grupos de forma moderada não evidenciando nenhuma ação agonística ou de ataque, apenas atitudes de alerta com a aproximação de ambos os representantes na respectiva área de uso); Evento VI - utilização de ninho de ave como local de pernoite.

A ocorrência dos eventos I, II, III e IV foi comparada entre as estações do ano (seca e chuvosa), turnos diários (manhã ou tarde), estratos ocupados (sub-bosque, estrato médio ou dossel), idade do sagüi (adulto ou infante) e sexo do sagüi (macho ou fêmea). Para tal utilizou-se o qui-quadrado $\left(\chi^{2}\right)$ de independência de dois eventos com confiança de $95 \%$. Foram considerados significativos os valores de $\mathrm{p} \leq 0,05$ e altamente significativos os de $\mathrm{p} \leq 0,01$. Para os estratos ocupados, definiu-se como sub-bosque (altura de até três metros), estrato médio (altura acima de três metros) e dossel (na copa das árvores), a altura das árvores foi mensurada por meio de um ipsometro e, também, por estimativa visual.

\section{RESULTADOS}

Das 5.040 horas de observações, foram registradas 96 ocorrências dos seis tipos de eventos listados, envolvendo 29 espécies de aves de 16 famílias e o Callithrix jacchus (Tab. I). Os comportamentos ocorridos entre os dois grupos estudados (aves x sagüis) são descritos a seguir:

\section{Evento I: predação de sagüis}

Tentativas de predação: quatro espécies de aves, Rupornis magnirostris (Gmelin, 1788), Buteo brachyurus Vieillot 1816, Cathartes aura (Linnaeus, 1758), e Botaurus pinatus (Wagler, 1829) (Tab. I), foram observadas em várias tentativas de captura de sagüis, principalmente jovens e infantes. Em uma destas tentativas, R. magnirostris obteve sucesso capturando um filhote de sagüi. Para as três primeiras espécies de aves citadas os eventos ocorreram, em geral, quando os sagüis encontravam-se no dossel e estavam desatentos ao ataque do predador ou ao raiar do dia quando começavam a despertar. As aves envolvidas davam sobrevôos rasantes na copa das árvores para capturarem jovens ou infantes que se encontravam nas costas dos integrantes mais velhos dos grupos. Apenas um evento ocorreu com B. pinatus no sub-bosque em que os sagüis emitiam vocalização de alarme e exibiam postura ameaçadora para a ave. 
Tabela I. Espécies de aves envolvidas nos eventos registrados durante a pesquisa. Eventos de acordo com as variáveis analisadas na Estação Ecológica do Tapacurá, Pernambuco: (I) predação de sagüis, (II) predação de aves, (III) disputa de área de forrageio e recurso alimentar, (IV) compartilhamento de área de forrageio e recurso alimentar, (V) perseguição branda, (VI) utilização de ninho como local de pernoite.

\begin{tabular}{|c|c|c|c|c|c|c|c|c|c|}
\hline \multirow{2}{*}{ Evento } & \multirow{2}{*}{ Espécies } & \multicolumn{2}{|c|}{ Estação } & \multicolumn{2}{|c|}{ Turno } & \multicolumn{3}{|c|}{ Estrato } & \multirow{2}{*}{ Tota } \\
\hline & & Seca & Chuva & Manhã & Tarde & Subosque & Médio & Dossel & \\
\hline \multirow[t]{4}{*}{1} & Botaurus pinatus (Wagler, 1829) & 1 & & & 1 & 1 & & & 1 \\
\hline & Cathartes aura (Linnaeus, 1758) & 2 & 8 & 6 & 4 & & 1 & 9 & 10 \\
\hline & Rupornis magnirostris (Gmelin, 1788) & 5 & 7 & 8 & 4 & & 2 & 10 & 12 \\
\hline & Buteo brachyurus Vieillot, 1816 & & 2 & 1 & 1 & & & 2 & 2 \\
\hline \multicolumn{2}{|c|}{ Sub-total } & 8 & 17 & 15 & 10 & 1 & 3 & 21 & 25 \\
\hline \multirow[t]{11}{*}{ II } & Columbina minuta (Linnaeus, 1766) & 1 & 2 & 3 & & 2 & & 1 & 3 \\
\hline & Columbina talpacoti (Temminck, 1811) & 2 & 1 & 3 & & 3 & & & 3 \\
\hline & Nyctidromus albicollis (Gmelin, 1789) & & 1 & 1 & & 1 & & & 1 \\
\hline & Phaethornis ruber (Linnaeus, 1758) & 1 & & 1 & & 1 & & & 1 \\
\hline & Eupetomena macroura (Gmelin, 1788) & 1 & & 1 & & 1 & & & 1 \\
\hline & Formicivora grisea (Boddaert, 1783) & & 1 & 1 & & 1 & & & 1 \\
\hline & Elaenia flavogaster (Thunberg, 1822) & 2 & 1 & 2 & 1 & 3 & & & 3 \\
\hline & Pitangus sulphuratus (Linnaeus, 1766) & 2 & & 2 & & 1 & 1 & & 2 \\
\hline & Pachyramphus polychopterus (Vieillot, 1818) & 3 & 1 & 2 & 2 & & 4 & & 4 \\
\hline & Polioptila plumbea (Gmelin, 1788) & 5 & 3 & 4 & 4 & 7 & 1 & & 8 \\
\hline & Turdus leucomelas Vieillot, 1818 & 1 & & 1 & & 1 & & & 1 \\
\hline \multicolumn{2}{|c|}{ Sub-total } & 18 & 10 & 21 & 7 & 21 & 6 & 1 & 28 \\
\hline \multirow[t]{7}{*}{ III } & Crotophaga ani Linnaeus, 1758 & 6 & & 5 & 1 & 6 & & & 6 \\
\hline & Veniliornis passerinus (Linnaeus, 1766) & 1 & & 1 & & & & 1 & 1 \\
\hline & Taraba major (Vieillot, 1816) & 4 & 2 & 6 & & 6 & & & 6 \\
\hline & Xiphorhynchus picus (Gmelin, 1788) & 3 & 1 & 4 & & 2 & 2 & & 4 \\
\hline & Turdus rufiventris Vieillot, 1818 & 1 & & & 1 & 1 & & & 1 \\
\hline & Turdus leucomelas Vieillot, 1818 & 1 & 3 & 2 & 2 & 2 & 2 & & 4 \\
\hline & Tangara cayana (Linnaeus, 1766) & & 3 & 3 & & 2 & 1 & & 3 \\
\hline \multicolumn{2}{|c|}{ Sub-total } & 16 & 9 & 21 & 4 & 19 & 5 & 1 & 25 \\
\hline \multirow[t]{6}{*}{ IV } & Piaya cayana (Linnaeus, 1766) & 8 & & 6 & 2 & 5 & 2 & 1 & 8 \\
\hline & Thamnophilus palliatus (Lichtenstein, 1823) & & 2 & & 2 & 2 & & & 2 \\
\hline & Thamnophilus caerulescens Vieillot, 1816 & 1 & & 1 & & 1 & & & 1 \\
\hline & Synallaxis frontalis Pelzeln, 1859 & & 1 & 1 & & 1 & & & 1 \\
\hline & Myiozetetes similis (Spix, 1825) & 2 & & 1 & 1 & 2 & & & 2 \\
\hline & Thryothorus genibarbis Swainson, 1838 & 1 & 1 & 2 & & 2 & & & 2 \\
\hline \multicolumn{2}{|c|}{ Sub-Total } & 12 & 4 & 11 & 5 & 13 & 2 & 1 & 16 \\
\hline $\mathrm{V}$ & Nyctibius griseus (Gmelin, 1789) & 1 & & 1 & & & 1 & & 1 \\
\hline \multicolumn{2}{|c|}{ Sub-Total } & 1 & & 1 & & & 1 & & 1 \\
\hline $\mathrm{VI}$ & Phacellodomus rufifrons (Wied, 1821) & 1 & & & 1 & & 1 & & 1 \\
\hline \multicolumn{2}{|c|}{ Sub-total } & 1 & & & 1 & & 1 & & 1 \\
\hline Total & 56 & 40 & 69 & 27 & 54 & 18 & 24 & 96 & \\
\hline
\end{tabular}

Comportamento antipredatório: os sagüis quando ameaçados pelas aves, emitiam forte vocalização de alerta e a este sinal os infantes se aproximavam dos adultos e o grupo coeso se reunia e se escondia embaixo das folhagens ou descia rapidamente pelos troncos das árvores até o solo. Observou-se, também, que em investidas de captura por gaviões ou urubus, os 
pais transferiam os filhotes das costas para a região próxima ao ventre.

\section{Evento II: predação de aves}

Predação de ovos e filhotes de aves por sagüis: onze espécies de aves tiveram seus ninhos atacados pelos sagüis na época reprodutiva (Tab. I), sendo Polioptila plumbea (Gmelin, 1788) a espécie de ave que teve o maior número de ocorrências registradas $(\mathrm{N}=8)$. Apesar do comportamento agressivo de algumas espécies de aves direcionado ao predador, muitas vezes os sagüis conseguiam retirar do ninho tanto ovos quanto filhotes de aves para se alimentarem. Geralmente, os dominantes do grupo executavam o ataque e os jovens e infantes de sagüis requisitavam parte do alimento obtido.

Comportamento antipredatório: em algumas espécies de aves a defesa era feita pelo casal que atacava os sagüis dando sobrevôos rasantes seguidos de pancadas com o bico ou com o peito na cabeça dos sagüis, até que estes se distanciassem das proximidades do ninho. As espécies que exibiram este comportamento de defesa foram: Eupetomena macroura (Gmelin, 1788), Phaethornis ruber (Linnaeus, 1758), Formicivora grisea (Boddaert, 1783), Elaenia flavogaster (Thunberg, 1822), Pitangus sulphuratus (Linnaeus, 1766), Pachyramphus polychopterus (Vieillot, 1818), Turdus leucomelas Vieillot, 1818 e P. plumbea. Também foi observado o comportamento de fuga da ave adulta para longe do ninho por Columbina minuta (Linnaeus, 1766), C. talpacoti (Temminck, 1811) e Nyctidromus albicollis (Gmelin, 1789), de forma a desviar a atenção do predador.

\section{Evento III: disputa de recurso alimentar}

Este evento envolveu sete espécies de aves (Tab. I) e os sagüis, como conseqüência da invasão da área de forrageio de um determinado grupo de sagüi por algumas espécies de ave e vice-versa, como também, da disputa pelo recurso almejado. Em geral, esse evento esteve associado à saída das formigas de correição, que afugentavam insetos, aranhas e pequenos vertebrados que se tornavam presa fácil das aves e sagüis. Taraba major (Vieillot, 1816) e Crotophaga ani Linnaeus 1758, assumiam postura agressiva e atacavam os sagüis até afastá-los da sua área de forrageio. Outras espécies como o Turdus rufiventris Vieillot, 1818 e o T. leucomelas também disputavam as presas disponíveis durante a saída das formigas de correição. Indivíduos de T. major apresentavam comportamento agressivo quando seguidos pelos sagüis durante seu forrageio, nas bromélias visitadas, por onde as formigas de correição passavam desalojando pequenos vertebrados e artrópodes.

Também foi observada, em época de frutificação do caju, a disputa do fruto entre jovens sagüis e Tangara cayana (Gmelin, 1789). Outro recurso disputado foi o oco de árvores onde poderiam ser encontradas larvas de insetos. A disputa foi observada entre duas espécies de aves e os sagüis. As espécies de aves envolvidas neste evento foram Xiphorhynchus picus (Gmelin, 1788) e Veniliornis passerinus (Linnaeus, 1766), que defenderam agressivamente o recurso alimentar. As aves exibiam com- portamento de defesa emitindo vocalização, além de levantarem e baterem as asas energicamente, circundando o sagüi até que este se afastasse de sua área de forrageio.

\section{Evento IV: divisão de área de forrageio}

Ao contrário da disputa do recurso alimentar, algumas aves compartilhavam a área de forrageio, particularmente as áreas em que estavam as formigas de correição, com os sagüis. Seis espécies de aves apresentaram esse comportamento: Piaya cayanna (Linnaeus, 1766), Thamnophilus palliatus (Lichtenstein, 1823), T. caerulescens Vieillot, 1816, Myiozetetes similis (Spix, 1825), Synalaxis frontalis Pelzeln, 1859 e Thryothorus genibarbis Swainson 1838 (Tab. I). Apesar de dividirem o espaço onde se encontrava o alimento, observou-se que as aves e os sagüis mantinham certa distância uns dos outros(cerca de 2 a 3 metros).

O comportamento de roubo de presas que eram carregadas pelas formigas de correição foi apresentado por $P$. cayana, C. ani e pelos sagüis. Os sagüis capturavam a presa sacudiam as mãos e limpavam-se para retirar as formigas do corpo.

\section{Evento V: perseguição branda}

Ocorreu entre o Nyctibius griseus (Gmelin, 1789) e um sagüi com aproximações persistentes de ambos os participantes até que um deles se afastasse. Essas ações, por vezes, duravam minutos. Aparentemente as espécies envolvidas se alternavam, assumindo posturas seqüenciais de alerta como uma defesa da área de uso.

\section{Evento Vl: utilização de ninho de ave como local de pernoite}

Foi registrado o uso contínuo de um ninho desabitado do graveteiro, Phacellodomus rufifrons (Wied, 1821), por um grupo de seis sagüis durante quase uma semana. O ninho serviu de abrigo durante os pernoites.

\section{Análise estatística}

Ocorreu maior número de eventos de disputa de alimentos no período seco comparado ao chuvoso $\left(\chi^{2}=12,70\right.$; g.l. 6 ; $\mathrm{p}$ $<0,05)$ e, também, de divisão de alimentos $\left(\chi^{2}=13,33\right.$; g.l. 5; $p=0,02$ ). Os demais eventos também foram comparados com a estação do ano não obtendo diferenças significativas (predação de sagüis $\chi^{2}=4,24$; g.l. 3 ; $p=0,24$; predação de aves $\chi^{2}=7,86$; g.1.10; $\mathrm{p}=0,64)$.

Quanto aos turnos (manhã e tarde) de ocorrência dos eventos, não houve diferenças significativas (predação de sagüis $\chi^{2}=$ 1,81; g.l. 3; $\mathrm{p}=0,25$; predação de aves $\chi^{2}=8,44$; g.1.10; $\mathrm{p}=0,59$; disputa $\chi^{2}=11,36$; g.l. 6 ; $\mathrm{p}=0,08$ e para divisão $\chi^{2}=6,69$; g.l. 5; $\mathrm{p}=0,25)$. Entretanto, foi observado um maior número de eventos ocorrendo no turno da manhã $(\mathrm{N}=69)$ (Tab. I).

Quanto ao estrato ocupado, apenas os eventos de predação de sagüis e disputa de recurso alimentar obtiveram diferenças significativas (predação de sagüis $\chi^{2}=25,56$; g.l. 6; $\mathrm{p}<0,01$ e disputa de recurso $\chi^{2}=33,16 ; \mathrm{n}=25 ; \mathrm{p}<0,01$ ), onde se observou uma maior predação de sagüis no dossel. Já para as disputas de recursos alimentares a grande maioria das ocorrências aconteceu no sub-bosque. Os demais eventos não foram 
significativos (predação de aves $\chi^{2}=28,19 ;$ g.1.20; $\mathrm{p}=0,15$ e para divisão $\chi^{2}=3,69$; g.l. 10; $\left.\mathrm{p}=0,96\right)$.

A comparação de todos os eventos testados (I, II, III e IV) agrupados e relacionados ao estrato ocupado obteve diferença altamente significativa $\left(\chi^{2}=67,59 ; \mathrm{n}=94 ; \mathrm{p}<0,01\right)$, sendo o sub-bosque o estrato com maior número de eventos registrados (Tab. I). Esses mesmos eventos comparados à estação do ano também obtiveram diferenças significativas $\left(\chi^{2}=9,61\right.$; g.l. $=3$; $\mathrm{p}=0,02)$, sendo observado um maior número de eventos na estação seca (Tab. I). Entretanto, quanto aos turnos diários analisados os resultados dos testes não foram significativos $\left(\chi^{2}=3,80\right.$; g.l. $=3 ; \mathrm{p}=0,28)$.

Houve diferenças significativas quanto à predação de aves por parte dos sagüis em relação ao sexo e idade do mesmo. Observou-se que os machos efetuaram maior número de predação do que as fêmeas $\left(\chi^{2}=23,00 ;\right.$ g.l. $=9$; $\left.\mathrm{p}<0,01\right)$, em relação a idade os adultos foram os que efetuaram o maior número de predações $\left(\chi^{2}=24,00\right.$; g.l. $=10$; $\left.\mathrm{p}<0,01\right)$. Os indivíduos machos e adultos foram os que efetuaram maior predação quando comparados às fêmeas e juvenis (Tab. II).

\section{DISCUSSÃO}

\section{Predação de sagüis}

As aves consideradas predadoras ou que pelo menos provocavam reações de ameaça nos sagüis foram duas espécies de gaviões, uma de urubu e uma de socó. A tentativa de predação de sagüis foi um dos eventos mais observados nesta pesquisa, apesar de praticamente todos os eventos serem constituídos de tentativas sem sucesso, principalmente pelo comportamento antipredatório apresentado pelos sagüis. Os primatas têm comportamento agressivo e de emissão da vocalização de alarme mediante a presença de predadores (CHENEY \& WRANGHAM 1987, Heymann 1990, Galleti 1996), o que também foi registrado neste estudo.
Há registros de falconiformes se alimentando de primatas na literatura como, por exemplo, Rupornis magnirostris e Leucopternis albicollis Latham 1790, como prováveis predadores de Saimiri oerstedii Reinhardt, 1872 e Morphnus guianensis (Daudin, 1800) como predador de Ateles paniscus (Linnaeus, 1758), Saguinus mystax (Spix, 1823) e Saguinus fuscicollis (Spix, 1823), Harpyia harpia como predador de Chiropotes utahicki e Spizaetus tyrannus como predador de Allouata guariba (BoINSKI \& Scott 1988, Julliot 1994, Vasquez \& Heymann 2001, Martins et al. 2005, Miranda et al. 2006). Por outro lado, Sick (1997) não faz referência a sagüis como item alimentar de $R$. magnirostris e Buteo brachyurus sendo a alimentação descrita constituída de insetos e pequenos vertebrados (e.g. sapos, rãs, lagartixas, pássaros e morcegos).

O hábito de Cathartes aura (urubu-de-cabeça-vermelha) é totalmente necrófago (SICK 1997). Devido ao mimetismo existente entre esta espécie e Buteo albonotatus Kaup, 1847 (SICK 1997), acredita-se que as reações exibidas pelos sagüis aos vôos rasantes de C. aura, ocorreram em decorrência do referido mimetismo.

Quanto à espécie Botaurus pinatus, sua dieta é constituída por sapos, cobras e preás (SıcK 1997), não existindo registro de primatas compondo sua dieta, sendo assim, o registro, neste estudo, dessa espécie de ave como predadora de sagüis seria o primeiro.

O comportamento de defesa dos sagüis, frente à ameaça de predação, é condizente com reações observadas em outras espécies de macacos, principalmente no que se refere à aproximação dos infantes aos pais, mediante vocalização de alerta (DiAs \& STRIER 2000), bem como a vocalização de alerta, o silêncio do grupo escondido embaixo das folhagens no dossel e a descida rápida pelos troncos das árvores até o solo, também são ações observadas em outros primatas a exemplo de Allouata guariba, Saguinus fuscicollis e Cebus albifrons (Heymann 1990, Galleti 1996, Miranda et al. 2006).

Tabela II. Grupos e membros de sagüis envolvidos e número de eventos ocorridos na predação de aves de acordo com as variáveis analisadas (sexo e idade), na Estação Ecológica do Tapacurá, Pernambuco.

\begin{tabular}{|c|c|c|c|c|c|c|}
\hline \multirow{2}{*}{ Grupo } & \multirow{2}{*}{ Membros } & \multicolumn{3}{|c|}{ Sexo } & \multicolumn{2}{|c|}{ Idade } \\
\hline & & Macho & Fêmea & Indeterminado & Jovem & Adulto \\
\hline \multirow[t]{4}{*}{ Esmirradins } & ZV - macho reprodutor & 8 & & & & 8 \\
\hline & OQ - macho reprodutor & 1 & & & & 1 \\
\hline & QS - fêmea reprodutora & & 1 & & & 1 \\
\hline & Infante & & & 1 & 1 & \\
\hline \multirow[t]{4}{*}{ Esperancins } & WT - macho reprodutor & 3 & & & & 3 \\
\hline & SP - macho reprodutor & 2 & & & & 2 \\
\hline & VS - fêmea não reprodutora & & 1 & & & 1 \\
\hline & TQ - fêmea não reprodutora & & 4 & & & 4 \\
\hline \multirow[t]{2}{*}{ Espivitadins } & LM - macho reprodutor & 1 & & & & 1 \\
\hline & B - fêmeainfante & & 2 & & 2 & \\
\hline Alagadins & Z - fêmeainfante & & 1 & & 1 & \\
\hline Total & 11 & 15 & 9 & 1 & 4 & 21 \\
\hline
\end{tabular}




\section{Predação de aves}

Há poucos relatos de predação de aves por sagüis. Pouco se sabe sobre este tipo de associação, ao contrário da predação de sagüis por aves. Alguns exemplos podem ser citados, como a predação de ovos de aves por primatas como Saimiri oerstedii, Callithrix penicillata E. Geoffroyi, 1812 e Cebus apella (Linnaeus 1758) (Boinski \& Scott 1988, Olmos 1990, Miranda \& Faria 2001, Ferreira et al. 2002). Outras espécies de animais também são citadas em literatura como predadores de ninhos de aves como tucanos, falcões de floresta, serpentes, lagartos e até formigas de correição (Robinson \& Robison 2001).

Foram observados comportamentos anti-predatórios das aves, como ataque aos predadores com pancadas de bico e peito em vôos rasantes e também a fuga para distante do ninho. Alguns comportamentos antipredatórios são observados nas aves como construção do ninho em lugares inacessíveis, camuflagem associação com vespeiros e formigueiros entre outros, além da defesa pelos pais que inclui o despistamento do ninho (SıcK 1997).

Não houve diferenças significativas na predação de aves quanto à estação do ano, período do dia e estrato ocupado. Entretanto, observou-se que o número de predações foi bem maior no período seco, que coincide com a baixa oferta de frutos e de insetos. A exploração de exudatos vegetais, principalmente na estação seca, quando a oferta de frutos se torna escassa, é um dos recursos alternativos utilizados por C. jacchus na Estação Ecológica de Tapacurá (SCALon et al. 1991). Indivíduos de Saguinus sp Hoffmannsegg 1807 na estação seca, quando a oferta de frutos diminui, passam a explorar outros recursos a exemplo do néctar (Garber 1993). Varella \& Yamamoto (1991), em pesquisas realizadas em laboratório, observaram que a disponibilidade de alimento interfere no comportamento exploratório e de forrageamento dos primatas.

O horário da manhã foi o que obteve maior número de predações o que pode ser explicado pela maior atividade dos grupos neste horário. O sub-bosque também concentrou maior predação de ninhos, uma vez que a maioria das aves atacadas, nesse estudo, havia construído seus ninhos nesse estrato.

Em pesquisas realizadas na Guiana Francesa com Saimiri sciureus (Linnaeus 1758) percebeu-se a alimentação/forrageamento constituiu-se de $63 \%$ das atividades desenvolvidas e que o estrato ocupado em maior tempo por esses primatas foi o sub-bosque constituindo 41,7\% (Thorsy et al. 2002).

\section{Disputa de recurso alimentar}

A disputa de recursos ocorreu em maior número na estação seca, diferindo significativamente, quando a oferta de alimento diminui para ambos os grupos. Aves insetívoras ficam mais tempo associadas aos macacos (Saguinus) na estação úmida, sendo este o período de menor oferta de artrópodos em relação ao resto do ano na área em que foi desenvolvido o estudo por BoINSKi \& SCOTT (1988).

Os artrópodos foram os mais disputados entre aves e sagüis. Existe uma disputa entre aves de maior, médio e pequeno porte quanto aos itens relacionados (WILlis \& ONIKI 1992). A alta densidade, a escassez de alimento e a sobreposição de habitat entre espécies levam a uma alta freqüência de encontros interespecíficos, e consequentemente a um alto nível de competição direta ou indireta (WASER 1987).

Também foi registrada uma diferença significativamente maior de disputas no sub-bosque. Este resultado foi certamente influenciado pelo fato da maioria dos eventos de disputa ter ocorrido quando os grupos seguiam as formigas de correição.

O sexo e a idade dos sagüis foram determinantes na predação das aves. Indivíduos machos e adultos realizaram a predação mais vezes que as fêmeas e os jovens. Machos de Cebus capucinus (Linnaeus 1758) e C. apella, especialmente os dominantes, são predadores mais eficientes (PERRY \& Rose 1994, RosE 1997, FerReira et al. 2002).

\section{Divisão de área de forrageio}

O compartilhamento da área de forrageio foi bastante observado entre as aves e os sagüis na Estação Ecológica do Tapacurá, ocorrendo em maior número na estação seca. Em decorrência da diminuição dos recursos alimentares durante a estiagem, verificou-se que algumas aves e sagüis dividiam o mesmo espaço de forrageamento, principalmente relacionado às formigas de correição, já que as mesmas em suas saídas desalojam vários animais, desde artrópodos a pequenos vertebrados, que são consumidos por aves e sagüis.

Grupos mistos de forrageamento possuem maior adaptação e vantagem tornando-os mais eficientes e geralmente possuem espécies com dietas similares, forrageamento semelhante e mesmo habitat (Terborgh 1990). Alguns grupos constituem espécies comensais e se beneficiam de ações de outras para adquirirem seu alimento otimizando a busca por alguns tipos de recursos, esta associação ocupa um nicho ecológico alternativo para algumas espécies de aves (PAssos 1997).

Com a saída das formigas de correição muitos insetos tornam-se disponíveis ao ataque de várias espécies de aves especialistas e não especialistas (e.g. Cuculidae, Dendrocolaptidae, Furnariidae, Formicariidae, Tyrannidae, Pipridae, Muscicapidae e Troglodytidae) que ali encontram uma grande concentração de alimento (ONIKI 1972, ONIKI \& WilLis 1972, WiLlis \& ONIKI 1992).

Associações ecológicas entre aves e macacos já foram registradas para famílias de aves como Dendrocolaptidae, Buconidae, Formicariidae e até Acciptridae e espécies de macacos. Essas aves seguem os sagüis em seus deslocamentos e/ou forrageamento, nos quais desalojam pequenos animais de seus abrigos, que são capturados, oportunísticamente, pelas aves (Passos 1997, Zhang \& Wang 2000, Hankerson et al. 2006).

Observou-se o comportamento dos sagüis de sacudir as mãos para se livrar das formigas que subiam por elas durante roubo de pequenos vertebrados e/ou artrópodos que eram carregados pelas formigas. Esse comportamento também é relatado por Rylands et al. (1989) que trabalharam com Callithrix flaviceps (Thomas, 1903).

Com a saída das formigas de correição, afugentando pequenos artrópodos e vertebrados, houve compartilhamento e 
disputa da área de forrageio e do recurso alimentar entre os dois grupos estudados. O compartilhamento seria uma associação comensal, as presas que conseguem escapar das mãos dos Saguinus são utilizadas posteriormente por espécies de aves que seguem estes macacos (Bornski \& SCOTT 1988).

\section{Utilização de ninho de ave como local de pernoite}

O uso de um ninho desabitado do graveteiro (P. rufifrons) por um grupo de seis sagüis, com fins de abrigo durante o pernoite, foi observado apenas uma vez durante este estudo. Entretanto, a utilização de ninhos ativos ou inativos de aves por outros animais pode decorrer de perdas da prole de aves (SICK 1997).Exemplos na literatura relativos a ocupação de ninhos de aves por outras espécies animais incluem a ocupação de um ninho de furnarídeo (Oreophylax sp.) por um roedor (Oryzomys sp.), a ocupação de um ninho de Thryothorus sp. por uma perereca (Phyllomedusa sp.) como área de dormida durante o dia tendo como conseqüência o abandono do ninho pelas aves e, também, a ocupação de ninhos velhos por outros animais.

\section{CONSIDERAÇÕES FINAIS}

As associações existentes entre as aves estudadas e o Callithrix jacchus são de fundamental importância para a manutenção dessas espécies em ambiente natural. Mais de 15\% das espécies de aves listadas para a Estação Ecológica do Tapacurá estão envolvidas nas relações observadas.

O sistema de classificação comportamental aqui utilizado resultou em seis tipos de eventos, afiliativos ou agonísticos, envolvendo aves e C. jacchus. Devido ao caráter pioneiro da pesquisa faz-se urgente o incentivo a estudos mais abrangentes, que possam fortalecer os argumentos aqui levantados e fornecer maior confiabilidade às analises, particularmente às relativas à predação.

\section{AGRADECIMENTOS}

Ao CNPq pela concessão da bolsa à R.M. de Lyra Neves; à UFRPE por permitir o desenvolvimento desta pesquisa na Estação Ecológica do Tapacurá, aos colegas de pesquisa de campo pelo auxílio neste trabalho e a Elizabete R. da Silva pelas valiosas sugestões dadas ao texto.

\section{REFERÊNCIAS BIBLIOGRÁFICAS}

Andrade-Lima, D. 1970. Recursos vegetais de Pernambuco. Recife, Instituto de Pesquisas Agronômicas, Boletim Técnico 41, $32 \mathrm{p}$.

BoINski, S. \& P.E. SCOTT. 1988. Association of birds with monkeys in Costa Rica. Biotropica 20 (2):136-143.

Cheney, D.L. \& R.W. Wrangham. 1987. Predation, p. 227-239. In: B.B. Smuts; D.L. Cheney; R.M. Seyfarth; R.W. Wrangham \& T.T. Struhsaker (Eds). Primate Societies. Chicago, The University of Chicago Press, 565p.

Dias, L.G. \& K.B. Strier. 2000. Agonistic encounters between muriquis, Brachyteles arachnoids (Primates, Cebidae), and other animals at the Estação Ecológica de Caratinga, Minas Gerais, Brasil. Neotropical Primates 8 (4): 138-141.

Ferreira, R.; B.D. Resende; M. Mannu; E.B. Ottoni \& P. Izar. 2002. Bird Predation and prey-transfer in Brown capuchin monkeys (Cebus apella). Neotropical Primates 10 (2): 84-89.

Galleti, M. 1996. Comportamentos antipredatórios de quarto espécies de primatas nenhum sudeste fazem Brasil. Revista de Brasileira Biologia 56 (2): 203-209.

Garber, P.A. 1993. Feeding ecology and behavior of the genus Saguinus, p. 273-295. In: A.B. Rylands (Ed.). Marmosets and Tamarins. Oxford, Oxford University Press, 396p.

Hankerson, S.J.; J.M. Dietz \& B.E. Raboy. 2006. Associations between golden-headed lion tamarins and the bird community in the Atlantic Forest of Southern Bahia. International Journal of Primatology 27 (2): 487-495.

Heymann, E.W. 1990. Reactions of wild tamarins, Saguinus mystax and Saguinus fuscicollis, to avian predators. International Journal of Primatology 11: 327-337.

Julliot, C. 1994. Predation of a young spider monkey (Ateles paniscus) by a crested eagle (Morphnus guianensis). Folia primatologica 63 (2): 75-77.

Lyra-Neves, R.M.; A.M.I. Farias; W.R. Telino-Júnior; M.C. Arzua; M.N. Botelho \& M.C.A. Lima. 2000. Ectoparasitismo em aves silvestres (Passeriformes - Emberizidae) de Mata Atlântica, Igarassú, Pernambuco. Melopsittacus 3 (2): 64-71.

Lyra-Neves, R.M. De; A.M.I. de Farias \& W.R. Telino-Júnior. 2003. Ecological relationships between feather mites (Acari) and wild birds of Emberizidae (Aves) in a fragment of Atlantic Forest in northeastern Brazil. Revista Brasileira de Zoologia 20 (3): 481-485.

Lyra-Neves, R.M. DE; A.M.I. de Farias \& W.R. Telino-Júnior. 2005. Interações entre Phthiraptera (Insecta) e aves (Emberizidae) de Mata Atlântica, Pernambuco, Brasil. Ornithologia 1 (1): 43-47.

Machado, I.C. \& A.V. Lopes. 2003. Recursos florais e sistemas de polinização e sexuais em Caatinga, p. 515-563. In: I.R. LEAL; T. TABARElli \& J.M.C. DA Silva (Eds). Ecologia e conservação da caatinga. Recife, Editora Universitária UFPE, 822p.

Martins, S. de S.; E.M. de Lima \& J. de S. Silva JR. 2005. Predation of a bearded saki (Chiropotes utahicki) by a harpy eagle (Harpyia harpyia). Neotropical Primates 13 (1): 7-10.

Miranda, G.H.B. DE \& D.S. DE Faria. 2001. Ecological aspects of black-pincelled marmoset (Callithrix penicillata) in the Cerradão and Dense Cerrado of the Brazilian Central Plateau. Brazilian Journal of Biology 61 (3): 397-404.

Miranda, J.M.D.; I.P. Bernardi; R.F. Moro-Rios \& F.C. Passos. 2006. Antipredator behavior of brown howlers attacked by Black Hawk-eagle in Southern Brazil. International Journal of Primatology 27 (4): 1097-1101.

Olmos, F. 1990. Nest predation of plumbeous ibis by capuchin monkeys and greater black hawk. Wilson Bulletin 102 (1): 169-170. 
ONIKI, Y. 1972. Studies of the guild of ant-following birds at Belém, Brazil. Acta Amazônica 2 (1): 59-79.

ONIKI, Y. \& E. WiLLIS. 1972. Studies of ant-following birds north of the eastern Amazon. Acta Amazônica 2 (2): 127-145.

PAssos, F. DE C. 1997. A foraging association between the olivaceous woodcreeper Sittasomus griseicapillus and black lion tamarin Leontopithecus chrysopygus in southeastern Brazil. Ciência e Cultura 49 (1/2): 144-145.

Perry, S. \& L. Rose. 1994. Begging and transfer of coati meat by White-faced capuchin monkeys, Cebus capucinus. Primates 35 (4): 409-415.

Piratelli, A. \& M.R. Pereira. 2002. Dieta de aves na região leste de Mato Grosso do Sul, Brasil. Ararajuba 10 (2): 131-139.

Robinson W.D. \& T.R. Robinson. 2001. Observations of predation events at bird nests in Central Panama. Journal Field Ornithology 72 (1): 43-48.

Rodal, M.J.N.; M.F.A. Lucena; K.V.S.A. Andrade \& A.L. DE Melo. 2005. Mata do Toró: uma floresta estacional semidecidual de terras baixas no nordeste do Brasil. Hoehnea 32 (2): 283294.

Rose, L. 1997. Vertebrate predation and food-sharing in Cebus and Pan. International Journal of Primatology 18: 727765.

Rylands, A.B.; M.A.O. Monteiro da Cruz \& S.F. Ferrari. 1989. An association between marmosets and army ants in Brazil. Journal of Tropical Ecology 5: 113-116.

Scalon, C.E.; N.R. Chalmes \& M.A.O. Monteiro da Cruz. 1989. Home range use and the explotation of gum in the marmoset Callithris jacchus jacchus. International Journal of Primatology 10: 123-136.

Scalon, C.E.; M.A.O. Monteiro da Cruz \& A.B. Rylands. 1991. Exploração de exudatos vegetais pelo sagüi-comum, Callithris jacchus, p. 197-205. In: A.B. RYLANDs \& A.T. BERNARDEs (Eds). A Primatologia no Brasil. Belo Horizonte, Fundação Biodiversitas, vol. 3, 459p.

SICK, H. 1997. Ornitologia Brasileira. Rio de Janeiro, Editora Nova Fronteira, 912p.

Sigrist, T. 2006. Aves do Brasil: uma visão artística. São Paulo, Editora Leitura Dinâmica, 672p.

Siqueira Filho, J.A. de \& I.C. Machado. 2004. Síndrome de polinização de uma comunidade de Bromeliaceae e biologia floral de Vriesea psittacina (Hooker) Lindley (Bromeliaceae) em Brejos dos Cavalos, Caruaru, p. 277-284. In: K.C. PoRTo; J.J.P. Cabral \& M. Tabarelli (Eds). Brejos de altitude em
Pernambuco e Paraíba: história natural, ecologia e conservação. Brasília, Ministério do Meio Ambiente, 324p.

Stevenson, M.F. \& A.B. Rylands. 1988. The marmoset genus Callithrix, p. 131-222. In: R.A. Mittermeier; A.B. Rylands; A. CoImBRA-Filho \& G.A.B. FonseCA (Eds). Ecology and behaviour of Neotropical Primates. Washington, World Wildlife Foudation, 610p.

Stevenson, M.F. \& T.B. Poole. 1976. An ethogram of the common marmoset, Callithrix jacchus jacchus: general behavioural repertoire. Animal Behaviour 4: 428-451.

TERBORGH, J. 1990. Mixed flocks and polyspecific associations: costs and benefits on mixed groups to birds and monkeys. American Journal of Primatology 21: 87-100.

Thoisy, B. DE; O. Louguet; F. Bayart \& H. Contamin. 2002. Behavior of squirrel monkeys (Saimiri scireus) - 16 years on an Island in French Guiana. Neotropical Primates 10 (2): 73-76.

VARELLA, V.S. \& M.E. YамAмото., 1991. Influencia da disponibilidade de alimento sobre o comportamento exploratório de primatas, p. 57-61. In: A.B. Rylands \& A.T. Bernardes (Eds). A Primatologia no Brasil. Belo Horizonte, Fundação Biodiversitas, vol. 3, 459p.

Vasquez, M.R. \& E.W. Heymann. 2001. Crested eagle (Morphnus guianensis) predation on infant tamarins (Saguinus mystax and Saguinus fuscicollis, Callitrichinae). Folia Primatologica 72: 301-303.

Veloso, H.P.; A.L. R. Rangel Filho \& J.C.A. Lima. 1991. Classificação da vegetação brasileira, adaptada a um sistema universal. Rio de Janeiro, IBGE, 123p.

Vicente, A.; A.M.M. Santos \& M. Tabarelli. 2003. Variação no modo de dispersão de espécies lenhosas em um gradiente de precipitação entre floresta seca e úmida no nordeste do Brasil, 565-592. In: I.R. Leal; T. TABarelli \& J.M.C. DA Silva (Eds). Ecologia e conservação da caatinga. Recife, Editora Universitária UFPE, 822p.

WASER, P.E. 1987. Interactions among primate species, p. 210226. In: B.B. Smuts; D.L. Cheney; R.M. Seyfarth; R.W. Wrangham \& T.T. Struhsaker (Eds). Primate societies. Chicago, The University of Chicago Press, 565p.

Willis, E. \& ONIKI, Y. 1992. As aves e as formigas de correição. Boletim do Museu Paraense Emílio Goeldi, Série Zoologia, 8 (1): 123-150.

ZHANG, S. \& L. WANG. 2000. Following of brown capuchin monkeys by white hawks in French Guiana. The Condor 102 (1): 198201.

Recebido em 14.XI.2006; aceito em 16.VIII.2007. 